\title{
Decrease in the Transmembrane Sodium Activity Gradient in Ferret Papillary Muscle as a Prerequisite to the Calcium Paradox
}

\author{
Thomas Guarnieri \\ Department of Medicine, Division of Cardiology, The Johns Hopkins University School of Medicine, Baltimore, Maryland 21205
}

\begin{abstract}
Sodium-dependent calcium exchange may be an important mediator of calcium reperfusion damage during the calcium paradox phenomenon. We measured intracellular sodium activity with ion-selective electrodes during a 15-min period of calcium reperfusion in isolated ferret papillary muscles. During the calcium-free period, $\alpha \mathrm{Na}^{1}$ increased from $9.0 \pm 0.9$ to $18.9 \pm 4.3$ $\mathrm{mM}$. With reinstitution of calcium there was a significant contracture. The amount of contracture after calcium reinstitution was related to sodium loading during the calcium-free period. We were unable to block sodium entry during the calcium-free period with either nitrendipine, tetrodotoxin, or low concentrations of amiloride. $10^{-3} \mathrm{M}$ amiloride or lithium for sodium substitution in the calcium-free period, however, obliterated the increase in $\alpha \mathbf{N a}^{i}$ activity and the subsequent paradox. These data suggest that sodium loading is a necessary prerequisite for the calcium paradox and that one mechanism of sodium entry is through $\mathrm{Na}^{+} / \mathrm{Ca}^{2+}$ exchange. Under these conditions, no increase in the rest force is seen without previous sodium gains, suggesting that sodium-dependent calcium exchange is an important trigger for the calcium reflow, the calcium paradox.
\end{abstract}

\section{Introduction}

Reintroduction of calcium to cardiac muscle, after a period of calcium-free superfusion, causes variable degrees of contracture, tissue damage, and electromechanical dysfunction, the calcium paradox (1-4). The calcium paradox phenomenon has been a useful model for studying the effects of reperfusion on cardiac muscle, which are similar to what occurs across coronary artery stenosis. Most, if not all, studies have found that reflow with calcium results in remarkable cellular calcium overload (5-8). In turn, the calcium overload is hypothesized to be an important determinant of the mechanical dysfunction seen during calcium reperfusion $(3,4)$. The calcium overload and mechanical dysfunction may vary depending on a variety of experimental circumstances, and may be attenuated by a number of different interventions (9-12). Although recent studies suggest that the principal mechanism for calcium entry may be through the sodium-calcium exchange transporter, there are no data examining the relationship between the driv-

Address reprint requests to Dr. Thomas Guarnieri, The Peter Belfer Laboratory, Carnegie 530, Johns Hopkins Hospital, 600 N. Wolfe Street, Baltimore, MD 21205.

Received for publication 18 May 1987 and in revised form 4 January 1988.

J. Clin. Invest.

(C) The American Society for Clinical Investigation, Inc

0021-9738/88/06/1938/07 $\$ 2.00$

Volume 81, June 1988, 1938-1944 ing force of the exchange, the transmembrane sodium activity gradient, and the subsequent dysfunction $(6,7,12)$.

The sodium-calcium countertransport process is driven by the energy derived from the transmembrane sodium gradient $(6,13-16)$. Alterations in the gradient, either by reductions in perfusate sodium or increases in intracellular sodium content through sodium-potassium pump inhibition, have produced increases in the intracellular calcium (17-20). Additionally, the exchange process may be electrogenic, and as such, sensitive to the resting membrane potential (21).

If the sodium-calcium exchange is operative during calcium reperfusion, alterations in the sodium driving force should modify calcium reperfusion phenomena, and a threshold for alteration in the transmembrane sodium activity gradient should be definable. As such, we used sodium ion-sensitive electrodes to continuously measure the sodium gradient during the calcium-free period in isolated ferret papillary muscles and examined the relationship between changes in the transmembrane sodium activity gradient and subsequent changes in rest tension during the reperfusion period. In a few experiments, we were able to maintain impalements during the initial phase of the calcium reflow phenomenon, and were able to show the changes that occurred in the sodium gradient during the readmission of calcium.

Since increases in intracellular sodium content seem to be an important factor in the genesis of the calcium paradox, we used a series of blocking agents in experiments designed to ascertain whether sodium entry in this model was via sodiumcalcium exchange or through sodium or calcium channels, as has recently been suggested $(12,22)$.

\section{Methods}

Male ferrets (500-950 g; Marshall Research Animals, North Rose, NY) were anesthetized with anhydrous ether. The heart was excised and immersed in iced Tyrode solution. Right ventricular papillary muscles having diameters between 0.5 and $1.0 \mathrm{~mm}$ were removed.

Muscles were perfused in a modified fast-flow $4 \mathrm{~mm} \times 20 \mathrm{~mm}$ $\times 5.0 \mathrm{~mm}$ perfusion bath (23) with Tyrode solution with the following composition (in millimolars): $\mathrm{NaCl}, 135.4 ; \mathrm{KCl}, 4.0 ; \mathrm{NaH}_{2} \mathrm{PO}_{4}, 1.8$; $\mathrm{MgCl}_{2}, 0.5 ; \mathrm{NaHCO}_{3}, 18.0$; and dextrose, 20.0. $\mathrm{CaCl}_{2}$ was added to the solutions to produce a final concentration of $2.0 \mathrm{mM}$. Solutions were bubbled with $95 \%$ oxygen and $5 \% \mathrm{CO}_{2}$. The temperature was $36-37^{\circ} \mathrm{C}$ and the bath flow was kept at a rapid rate of $20 \mathrm{ml} / \mathrm{min}$. A parallel perfusion system was used for the calcium-free perfusate only. Rapid changes from the calcium-containing perfusate to the calcium-free perfusate were effected by using the parallel perfusion system.

The calcium-free perfusate was derived from water obtained from a deionization module, with calcium concentration $<10^{-7} \mathrm{M}$ (Nanopure; Barnstead Co., Sybron Corp., Boston, MA). To guarantee a calcium concentration $<10^{-7} \mathrm{M}$, the calcium-free perfusate contained $2.0 \mathrm{mM}$ EGTA $(7,8)$. Using a $K_{\mathrm{d}}$ of $3.26 \times 10^{6} \mathrm{M}^{-1}$, the free calcium concentration was calculated to be between $10^{-8}$ and $10^{-9} \mathrm{M}$. Since EGTA may interact with sodium during calcium-free perfusion, a companion series of experiments was performed in calcium-free water 
only (24). We saw no difference in the behavior of $\alpha \mathrm{Na}^{\mathrm{i}}$ or rest tension in these experiments and as such included these data in the results (Table I).

Conventional microelectrodes filled with $3 \mathrm{M} \mathrm{KCl}$ were constructed from thick-walled borosilicate glass (1B100; World Precision Instruments, New Haven, CT) resistances ranged between 10 and 30 $\mathrm{M} \Omega$ when filled with $3 \mathrm{M} \mathrm{KCl}$. The same glass was used to construct the sodium-sensitive electrodes in a manner previously described (25).

The sodium-sensitive electrodes were calibrated with pure solutions of $\mathrm{NaCl}$ ranging, in millimoles, between 1 and 150 , with the latter solution serving as the reference. Sodium electrodes were also calibrated in mixed sodium chloride-potassium chloride solutions having a total concentration of $150 \mathrm{mM}$, as previously described, and as used by other investigators $(1-6,16,25)$. The calibration procedure was performed using the values of the concentrations of the ions in the solutions, but the final values of the activities were calculated by using the sodium activity coefficient of $0.76(25)$. Values of activities are reported to enable literature comparisons.

The conventional $3 \mathrm{M} \mathrm{KCl}$ electrode was coupled to a high input impedance electrometer (Fd 223; World Precision Instruments). Ground was established using a $\mathrm{Ag}-\mathrm{AgCl}$ agar potassium chloride bridge. The signal from the ion selective electrode was also coupled to the high input impedance amplifier. The difference signal between the reference and sodium electrode was displayed on a strip chart recorder through DC amplifiers (13-4615-10; Gould Inc., Recording Systems Div., Cleveland, $\mathrm{OH}$ ) with a $15-\mathrm{Hz}$ cut-off filter and also displayed on a multimeter (501; Tektronix Inc., Beaverton, OR). Values of the strip chart recorder were used for graphic purposes but the actual voltages for the calibration were those displayed on the multimeter.

After the muscles were removed from the right ventricle they were placed in the fast-flow bath. The tendon of the muscle was attached by a thin silk thread to the transducer while the muscular insertion was fixed to a stainless steel clamp in the bath. The muscle was paced at 1 $\mathrm{Hz}$ (1830; WPI) using 3-ms constant current pulses at twice the diastolic threshold. The active and rest tension of the muscles were recorded through a linear force transducer (BG-50; Kulite Semiconductor Products, Co., Inc., Ridgefield, NJ) coupled to a transducer amplifier (13-4615-15; Gould Inc.). The transducer was calibrated using standard weights before and after each experiment and was linear between the ranges of $0-25 \mathrm{~g}$. With the transducer-amplifier system used, changes in force of $0.1 \mathrm{~g}$ were easily detectable. The muscle was allowed to equilibrate, pacing at $1 \mathrm{~Hz}$ for 30-60 min. After equilibration, the muscle was stretched to the peak of its length tension curve. After stretching, the muscle was allowed to reequilibrate for $\sim 1 / 2 \mathrm{~h}$ or until such time that the rest tension was relatively constant. Stimulation was then discontinued.

When the muscle was in the quiescent state, simultaneous impalements were obtained with the ion-selective and the reference electrode (25). Because of the difficulty in obtaining multiple impalements, the technique of a single continuous impalement was used. For the reference electrode a resting membrane potential of at least $-75 \mathrm{mV}$ was a

Table I. Maximum Increase in $\alpha \mathrm{Na}^{i}$ and Rest Force

\begin{tabular}{lcll}
\hline \multicolumn{1}{c}{ Perfusate } & $\begin{array}{c}\text { Control } \\
\left(\alpha \mathrm{Na}^{\mathrm{i}}\right)\end{array}$ & Zero $\mathrm{Ca}^{2+}$ & $\mathrm{Ca}^{2+}$ reflow \\
\hline & $m M$ & $\begin{array}{c}\text { \% control } \alpha \\
N a^{j}\end{array}$ & \% control $R F$ \\
& & $204 \pm 20^{*}$ & $145 \pm 28^{*}$ \\
$135 \mathrm{mM} \mathrm{Na}^{+}(n=9)$ & $9.1 \pm 1.8$ & $290 \pm 16^{*}$ & $224 \pm 26^{*}$ \\
$10^{-5} \mathrm{M}$ ouabain $(n=4)$ & $9.7 \pm 0.7$ & $2903 \pm 3^{*}$ \\
$65 \mathrm{mM}$ lithium $(n=4)$ & $9.9 \pm 1.1$ & $102 \pm 2$ & $103 \pm 2$ \\
$10^{-3} \mathrm{M}$ amiloride $(n=6)$ & $8.9 \pm 1.9$ & $103 \pm 2$ & $108 \pm 5$ \\
\hline
\end{tabular}

RF, rest force.

${ }^{*} P<0.05$ vs. control. requisite for a satisfactory impalement; for the sodium electrode at least $-130 \mathrm{mV}$ was required. A constant difference signal was one that did not vary by $>5 \mathrm{mV}$ after $2 \mathrm{~min}$. If after $2 \mathrm{~min}$ of simultaneous impalements the signals were constant, the perfusate was then switched to the experimental perfusate. Once the period of the calcium-free superfusion was over, all solutions were switched to the control Tyrode solution containing $2.0 \mathrm{mM} \mathrm{Ca}$. All values of $\alpha \mathrm{Na}^{i}$ and voltage were obtained before calcium-free perfusion and immediately before calcium reperfusion. Tension was compared before calcium-free perfusion and at peak contracture.

Four groups of experiments were performed. The first set was designed to alter the transmembrane sodium gradient during $15 \mathrm{~min}$ of calcium-free perfusion. The individual experiments are as follows: (a) perfusion with $135 \mathrm{mM}$ normal $\mathrm{NaCl} ;(b)$ perfusion with the addition of $10^{-5}$ Mouabain; (c) perfusion with the addition of $10^{-3} \mathrm{M}$ amiloride; and $(d)$ perfusion with low sodium perfusate, in which $65 \mathrm{mM}$ $\mathrm{LiCl}$ was substituted for $50 \%$ of the $\mathrm{NaCl}$.

During the first set of experiments, there was significant depolarization during the calcium-free period. Because depolarization, per se, alters $\alpha \mathrm{Na}^{\mathrm{i}}$, we performed three experiments in which the extracellular potassium was increased to $15 \mathrm{mM}$ before and during the calcium-free period.

The first and second series of experiments confirmed that the sodium gradient decreased during the calcium-free period. However, there was variability in the extent and time course of the increase in $\alpha$ $\mathrm{Na}^{\mathrm{i}}$, and the subsequent contracture. We therefore used a third experimental strategy to investigate the role of the gain in $\alpha \mathrm{Na}^{\mathrm{i}}$ and the subsequent contracture. In a second group of muscles perfused with the normal $\mathrm{NaCl}(135 \mathrm{mM})$ during the calcium-free period, we commenced calcium reinstitution at variable times, at one of two levels of sodium loading: increase in $\alpha \mathrm{Na}^{\mathrm{i}}$ to a level no greater than $12 \mathrm{mM}$, or increase in $\alpha \mathrm{Na}^{\mathrm{i}}$ to a level $>15 \mathrm{mM}$.

In the fourth group of experiments we used a series of agents to attempt blockade of sodium entry during the calcium-free period, in hopes of elucidating the mechanism of sodium gain. Muscles were perfused with either low concentrations of amiloride $\left(10^{-6} \mathrm{M}\right)$, nitrendipine $\left(10^{-5} \mathrm{M}\right)$, tetrodotoxin $\left(10^{-4} \mathrm{M}\right)$, or dichlorobenzámil $\left(10^{-5} \mathrm{M}\right)$.

Statistics. Values of ion activity, voltage, and tension are displayed as means and SD. Changes in these values were compared by one-way or two-way analysis of variance as necessary.

\section{Results}

$\mathrm{Na}$ loading and contracture. Fig. 1 displays the change in $\alpha \mathrm{Na}^{\mathrm{i}}$ during the calcium-free pefiod. In this representative muscle, $\alpha$ $\mathrm{Na}^{\mathrm{i}}$ increased from 9.1 to $21.5 \mathrm{mM}$ during the calcium-free period. Resting potential in this muscle decreased from -79 to $-59 \mathrm{mV}$. There appears to be a rapid decline in $\alpha \mathrm{Na}^{\mathrm{i}}$ with reperfusion, clearly preceding contracture. This change in the voltage of the difference signal $\left(\alpha \mathrm{Na}^{i}\right)$ is probably not due to electrode displacement, as displacement generally altered the voltage of the difference signal in the opposite direction. A significant contracture develops almost immediately after reperfusion and peaks in $\sim 5 \mathrm{~min}$. This change in force represents a rough index of the calcium gain. This muscle was the best example of the few experiments in which both reference electrode and the sodium electrode remained impaled for a few moments before dislodgement during the reperfusion contracture.

The changes in $\alpha \mathrm{Na}^{\mathrm{i}}$ during four perturbations aimed at altering the transmembrane sodium gradient before the readdition of calcium are displayed in Table $\mathrm{I}$. When the perfusate $\mathrm{NaCl}$ was $135 \mathrm{mM}, \alpha \mathrm{Na}^{\mathrm{i}}$ increased from $9.1 \pm 1.0$ to $19.1 \pm 4.1$ mM $(P<0.001)$. The calculated sodium driving force $\left(V_{\mathrm{Na}^{-}}\right.$ $\left.V_{\mathrm{M}}\right)$ decreased from $145 \pm 11$ to $102 \pm 14 \mathrm{mV}(P<0.01)$. Rest 


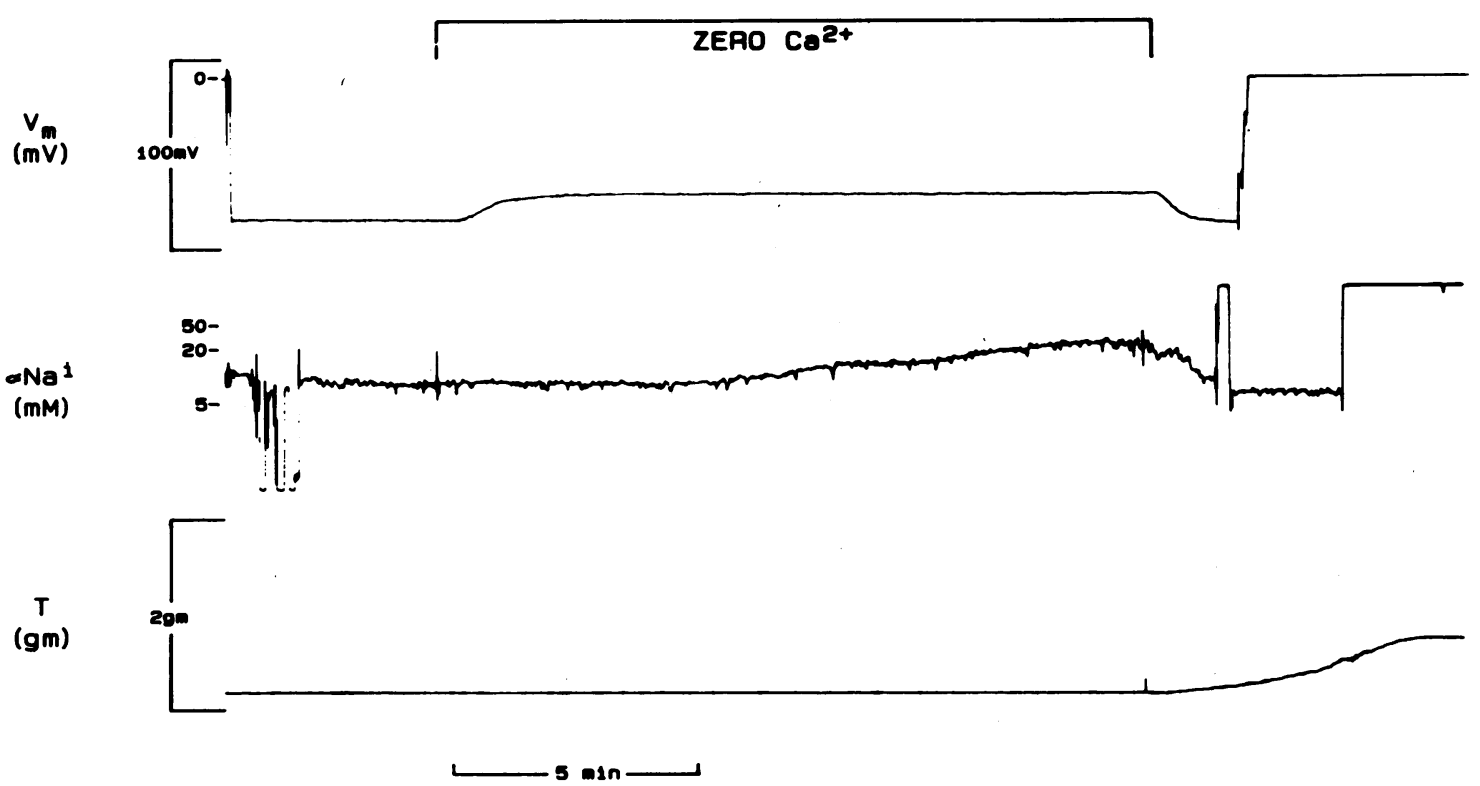

Figure 1. Displayed are resting potential $\left(V_{\mathrm{m}}\right)$, the difference signal $\left(V_{\mathrm{Na}}-V_{\mathrm{m}}\right)$ converted to $\alpha \mathrm{Na}^{\mathrm{i}}$, and rest force. With reperfusion, $\alpha \mathrm{Na}{ }^{\mathrm{i}}$ declines before contracture-induced electrode displacement.

tension increased by $145 \%$ after reinstitution of calcium. During the calcium-free perfusion there was variable but significant membrane depolarization: $-81 \pm 3$ to $-57 \pm 12 \mathrm{mV}(P$ $<0.01$ ).

When the normal perfusate contained ouabain (Fig. 2, Table I), $\alpha \mathrm{Na}^{\mathrm{i}}$ increased from $9.9 \pm 0.7$ to $27.9 \pm 6.2 \mathrm{mM}(P$ $<0.001$ ), while the sodium driving force decreased from $146 \pm 11$ to $84 \pm 12 \mathrm{mV}(P<0.01)$. Rest tension increased by $224 \%$. Of the perturbations listed in Table I, it was during the ouabain that the most consistent and significant membrane depolarization was seen, $-82 \pm 2$ to $-40 \pm 10 \mathrm{mV}(P<0.05)$. As seen in Fig. 2 and consistent with the effect of ouabain on the $\mathrm{Na}^{+} / \mathrm{K}^{+}$pump, no true steady state was reached in either $V_{M}$ or $\alpha \mathrm{Na}^{\mathrm{i}}$ over the time of the experiment.

When there was no change in $\alpha \mathrm{Na}^{\mathrm{i}}$, either with lithium substitution or the addition of high concentrations of amiloride $\left(10^{-3} \mathrm{M}\right)$ (see below), there was no significant gain in the rest tension. With lithium substitution, there was no gain in $\alpha$ $\mathrm{Na}^{\mathrm{i}}, 9.9 \pm 1.1$ to $10.1 \pm 2.3 \mathrm{~mm}$, or in rest force with calcium reinstitution. When relatively high concentrations of amiloride were present during the calcium-free period, there was also no significant change in $\alpha \mathrm{Na}^{\mathrm{i}}(8.9 \pm 1.9$ to $9.2 \pm 3.1 \mathrm{~mm})$ or in peak rest force after calcium reinstitution.

In Fig. 3 the percent gain in $\alpha \mathrm{Na}^{\mathrm{i}}$ before reperfusion vs. the percent gain in rest force after the readmission of calcium is plotted. Although there is a substantial correlation between gain in $\alpha \mathrm{Na}^{\mathrm{i}}$ and gain in rest force, $(r=0.80, P=0.06)$, the data could also be interpreted to indicate that without a gain in $\alpha \mathrm{Na}^{\mathrm{i}}$ during the calcium-free period, no contracture is seen with calcium reinstitution. That is, a critical shift in the so-

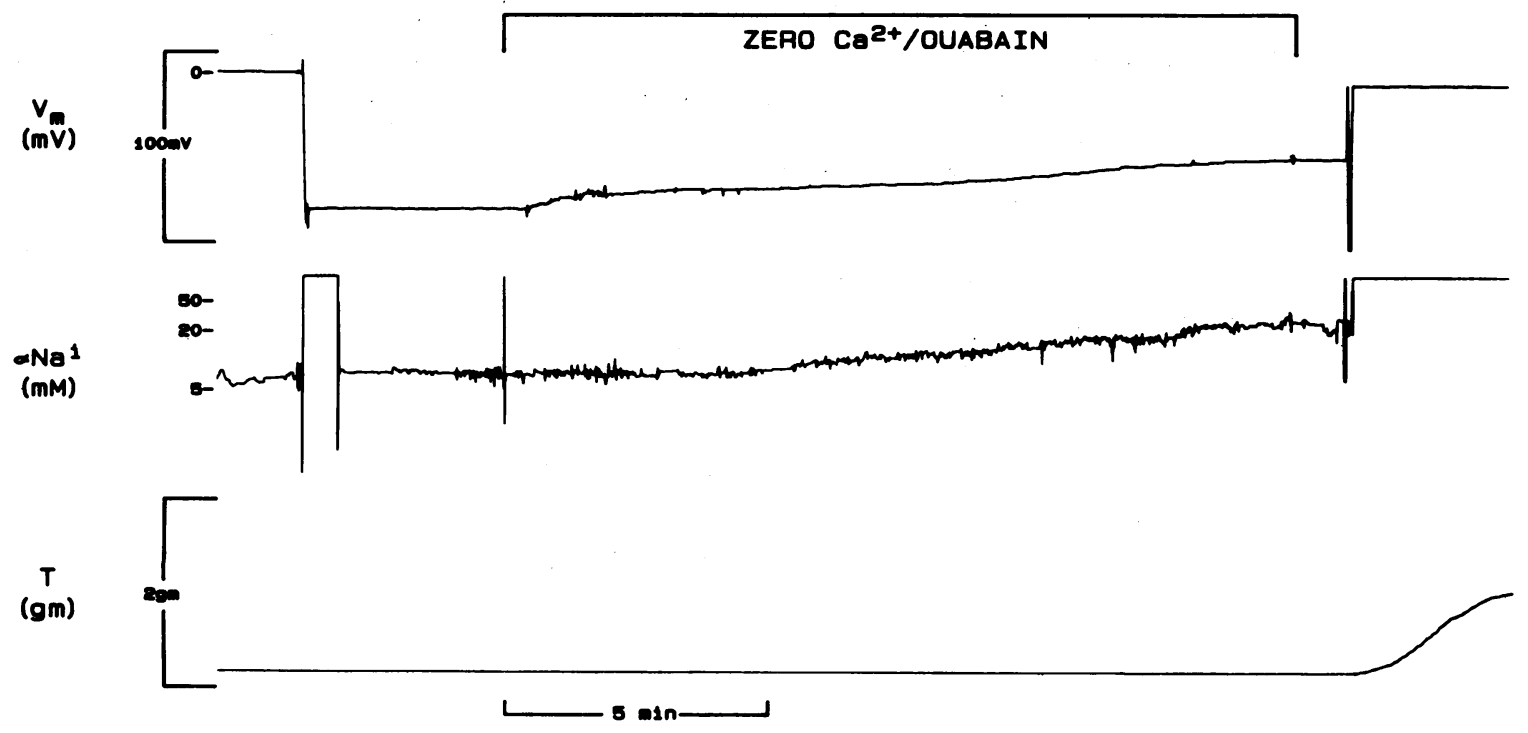

Figure 2. Ouabain-induced depolarization and increase in $\alpha \mathrm{Na}^{\mathrm{i}}$ during calcium-free perfusion. 


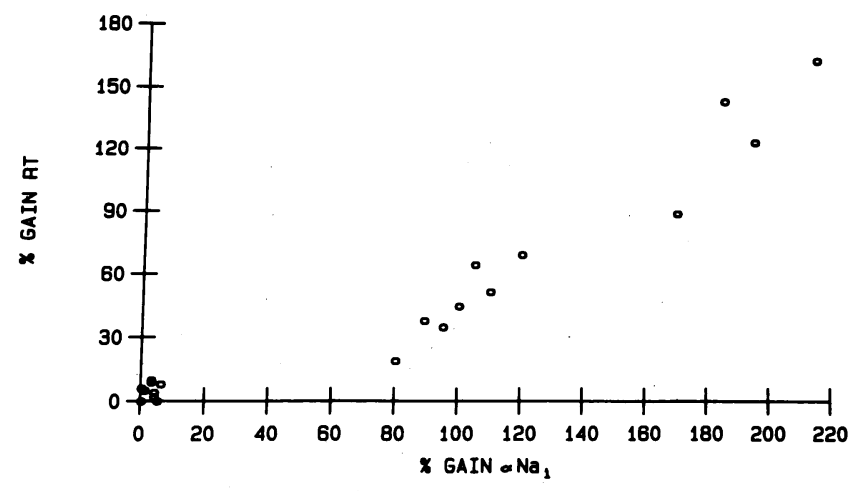

Figure 3. Peak $\alpha \mathrm{Na}^{\mathrm{i}}$ before reperfusion vs. peak rest tension after calcium reflow, both plotted as percent control.

dium force is necessary for contracture to occur in this model. Fig. 3 would suggest that this threshold must be on the order of 6 to $8 \mathrm{mM}$, as no shift in rest force is seen at lower gains in $\alpha$ $\mathrm{Na}^{\mathrm{i}}$. When we examined the relationship between the sodium driving force and the increase in rest force, we saw a similar relationship. As noted, there was variable but substantial depolarization in the calcium-free medium. To ascertain what role depolarization played in the changes in $\alpha \mathrm{Na}^{\mathbf{i}}$, three preparations were depolarized by $15 \mathrm{mM} \mathrm{KCl}$ before the calcium-free period. Fig. 4 displays the change in $\alpha \mathrm{Na}^{\mathrm{i}}$ with depolarization. The membrane potential depolarized from -79 to $-52 \mathrm{mV}$. After depolarization, $\alpha \mathrm{Na}^{\mathrm{i}}$ decreased from 9.1 to $5.0 \mathrm{mM}$. With calcium-free perfusion, however, $\alpha \mathrm{Na}^{\mathrm{i}}$ increased to 19.1 $\mathrm{mM}$. In three muscles, $\alpha \mathrm{Na}^{\mathrm{i}}$ increased from $9.2 \pm 1.3$ to $17.8 \pm 2.2 \mathrm{mM}$, while the rest force increased by $146 \pm 15 \%$. The calculated driving force decreased from $139 \pm 10$ to $136 \pm 11$ $\mathrm{mV}$ with $\mathrm{KCl}$ depolarization and to $104 \pm 11 \mathrm{mV}$ before reperfusion. These data suggested that the depolarization per se would not explain the changes in $\alpha \mathrm{Na}^{\mathrm{i}}$ or rest force.

These data suggested that a critical gain in $\alpha \mathrm{Na}^{\mathrm{i}}$ necessarily preceded a calcium reflow contracture. As noted in Table I, however, there was a good deal of variability in both the so- dium gain and the contracture. The hypothesis that a gain in $\alpha$ $\mathrm{Na}^{\mathrm{i}}$ was necessary for the calcium paradox was tested in six additional muscles using a prospective strategy. In these muscles, calcium reinstitution commenced when there was a variable gain in sodium: (a) an increase in $\alpha \mathrm{Na}^{\mathrm{i}}(n=3)$ to $<12$ $\mathrm{mM} ;(b) \alpha \mathrm{Na}^{\mathrm{i}}$ increase $>15 \mathrm{mM}(n=3)$.

Fig. 5 displays two experiments in which the time of calcium reinstitution was dependent on the gain in $\alpha \mathrm{Na}^{\mathrm{i}}$. In the top trace, $\sim 8 \mathrm{~min}$ of calcium-free perfusion was performed. No change in the sodium signal was seen. With readdition of calcium, no paradox was seen. Contrariwise, the bottom trace demonstrates that after $\sim 7$ min (a slightly shorter interval) when $\alpha \mathrm{Na}^{\mathrm{i}}$ had increased, a contracture was seen. In three muscles in which $\alpha \mathrm{Na}^{\mathrm{i}}$ increased from $8.3 \pm 1.2$ to $10.1 \pm 1.0$ $\mathrm{mM}$, rest force did not change, while in three muscles in which $\alpha \mathrm{Na}^{\mathrm{i}}$ increased from $9.1 \pm 1.4$ to $18.4 \pm 2.2 \mathrm{mM}(P<0.01)$, rest force increased to $138 \pm 20 \%$ control $(P<0.01)$. These experiments suggested that an increase in $\alpha \mathrm{Na}^{\mathrm{i}}$, not merely calcium-free perfusion, was a necessary prerequisite for the calcium reperfusion contracture.

In the third series of experiments, we sought to ascertain the mechanisms of sodium entry during the calcium-free period. Although these preparations were quiescent, it has been suggested that a calcium-free perfusate might alter the voltage dependence and channel specificity of the sodium and calcium channel $(12,22,26)$. Therefore, we exposed muscles during 15 min of a calcium-free period to $10^{-5} \mathrm{M}$ of the calcium channel blocker, nitrendipine $(n=3), 10^{-4} \mathrm{M}$ of the sodium channel blocker, tetrodotoxin $(n=3)$, or low doses $\left(10^{-6} \mathrm{M}\right)$ of the $\mathrm{Na}^{+} / \mathrm{Ca}^{2+}$ and $\mathrm{Na}^{+} / \mathrm{H}^{+}$, exchange blocker, amiloride $10^{-6} \mathrm{M}(n$ $=4)$, or the amiloride analogue, dichlorobenzamil $\left(10^{-5} \mathrm{M}\right)(n$ =3) (Table II).

As can be seen, blockade of the calcium channel with nitrendipine did not prevent sodium entry or a contracture in this preparation (Table II). Similarly, sodium channel blockade with tetrodotoxin did not prevent an increase in $\alpha \mathrm{Na}^{\mathrm{i}}$ or subsequent contracture. The data with low concentrations of amiloride should be contrasted with the above results and with that of $10^{-3} \mathrm{M}$ amiloride in Table $\mathrm{I}$. In a concentration range

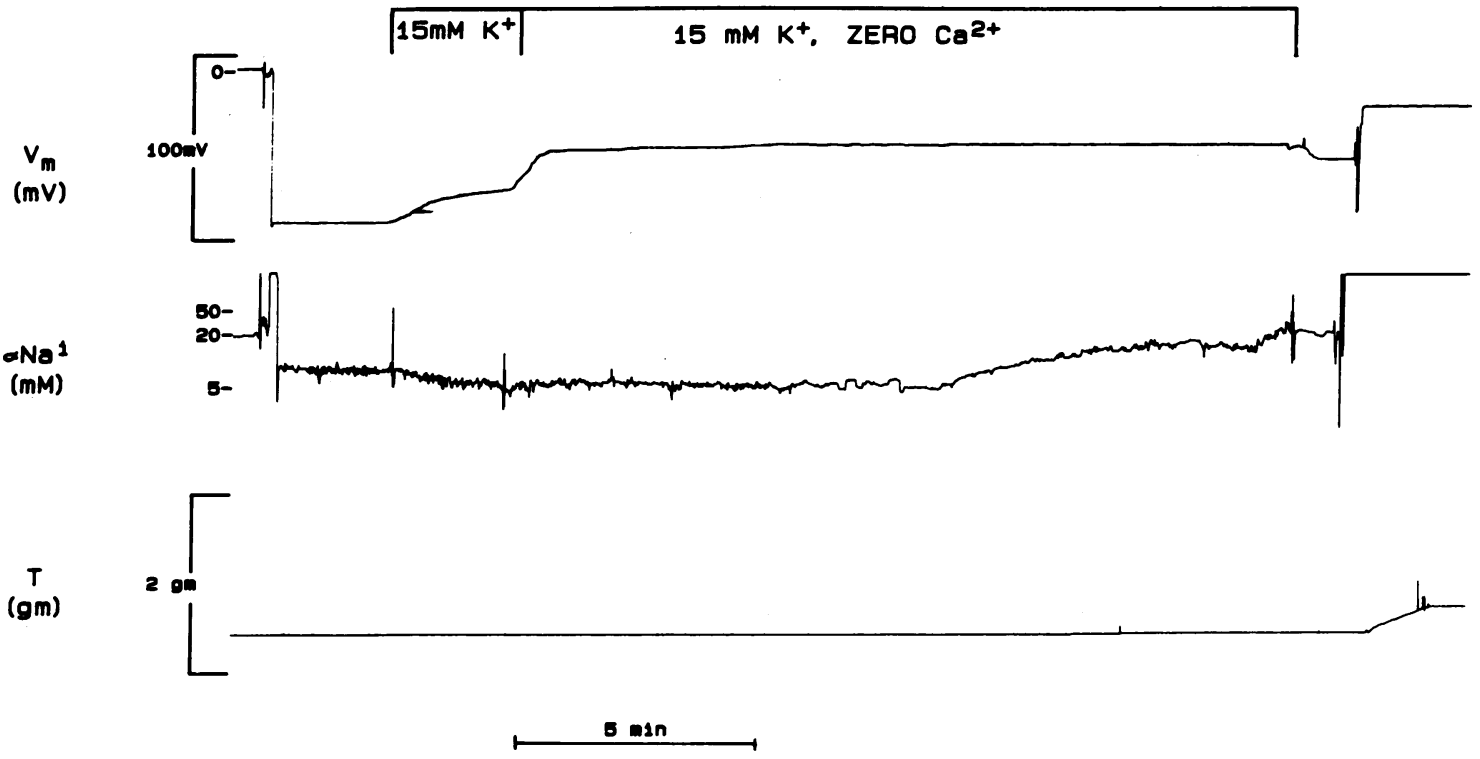

Figure 4. Peak $\alpha \mathrm{Na}^{\mathrm{i}}$ during potassium-induced depolarization, and during the calcium-free period. 


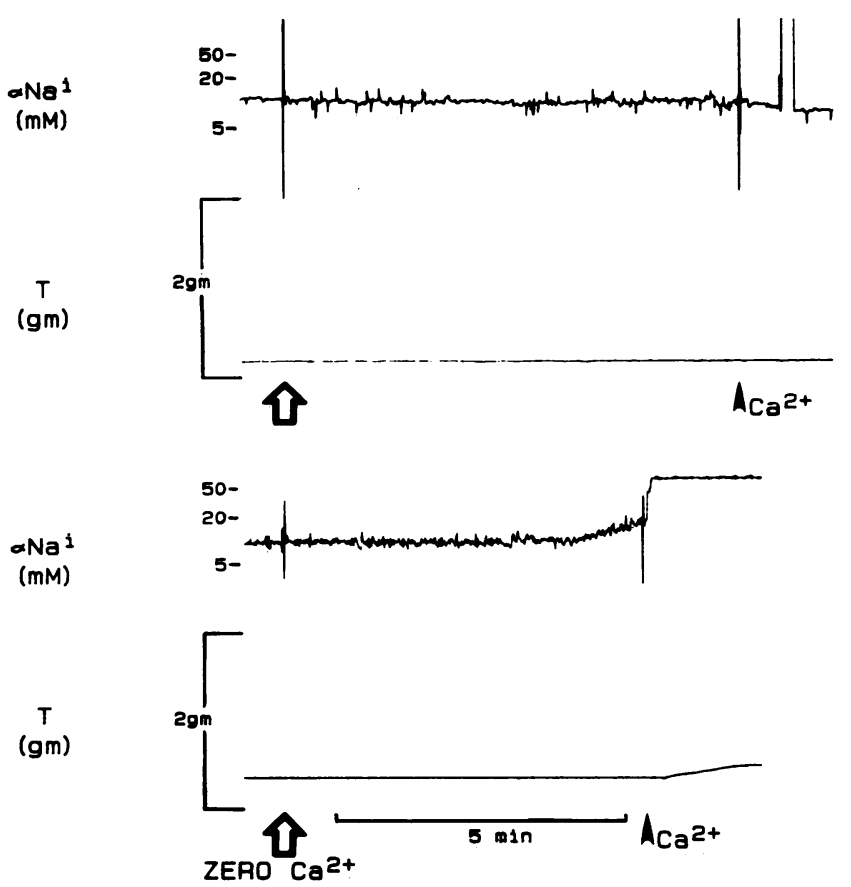

Figure 5. In the top panel, reflow commenced after $8 \mathrm{~min}$ with no gain in $\alpha \mathrm{Na}^{\mathrm{i}}$, while in the bottom trace $\alpha \mathrm{Na}^{\mathrm{i}}$ had increased (8.9 to $15.6 \mathrm{mM})$.

$\left(10^{-6} \mathrm{M}\right)$ where amiloride blocks $\mathrm{Na}^{+} / \mathrm{H}^{+}$exchange, there is still substantial gain in $\alpha \mathrm{Na}^{\mathbf{i}}$. It is only in the higher concentration range $\left(10^{-3} \mathrm{M}\right)$ when blockade of $\mathrm{Na}^{+} / \mathrm{Ca}^{+}$exchange occurs that the gain in $\alpha \mathrm{Na}^{\mathrm{i}}$ is blocked. The difference in the effects of amiloride, at different concentrations, and the lack of effect of nitrendipine and tetrodotoxin suggest that the path of sodium entry was at least partially through the $\mathrm{Na}^{+} / \mathrm{Ca}^{2+}$ exchange transporter. The suggested role of $\mathrm{Na} / \mathrm{Ca}$ exchange was also seen when the amiloride analogue, dichlorobenzamil $\left(10^{-3} \mathrm{M}\right)$ was superfused.

\section{Discussion}

The purpose of these experiments was to determine the role of transmembrane sodium gradient in the development of contracture when calcium is reintroduced to the superfusing solution in isolated ferret papillary muscle, the calcium paradox. The studies demonstrate that the relative gains in the rest tension during the readmission of calcium are related to the transmembrane sodium gradient just before reperfusion. It

Table II. Maximum Increases in $\alpha \mathrm{Na}^{i}$ on Rest Force

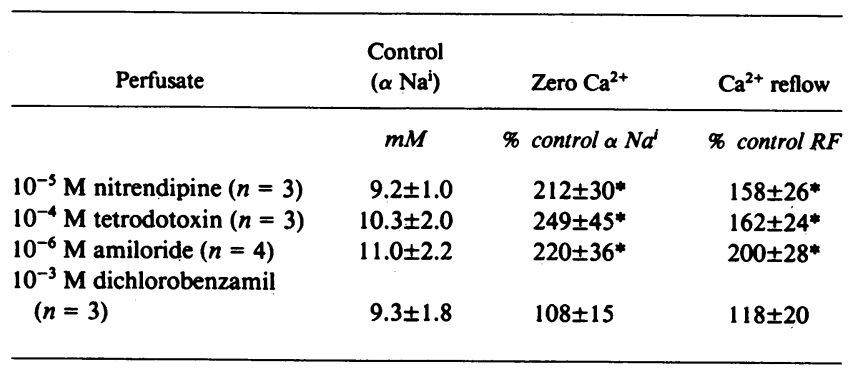

${ }^{*} P<0.05$ vs. control. was also noted that contracture was not seen unless the sodium gradient had been altered. In two experiments it was observed that there was a decline in the intracellular sodium activity, before calcium reflow contracture.

This study used ion-selective electrodes to measure the intracellular sodium activity in a continuous fashion in nonbeating tissue. There are well-known limitations to the absolute values of the sodium activity measured in this fashion (15, $25,27,28)$. These measurements, however, allow an on-line analysis of the shifts in the sodium gradient during the calcium-free period, and thus permitted a prospective experimental strategy, i.e., reintroducing calcium after variable shifts in the sodium gradient. One of the major difficulties in using these electrodes for these experiments was the inability to maintain impalements in beating muscle. Therefore, the values measured may be low when compared with beating preparations. Additionally, the readmission calcium contracture almost always (see below) displaced the electrodes. In two instances where dislodgement did not occur, we could observe the decrease in intracellular sodium activity before contracture, suggesting that there was a translocation of sodium and calcium preceding contracture.

A number of investigators have shown that the total cell sodium content rises during the calcium-free period $(7,8)$. Tunstall et al. (12), using sodium electrodes in four preparations, recently demonstrated in frog atria that $\alpha \mathrm{Na}^{\mathrm{i}}$ rises to 58 $\mathrm{mmol} / \mathrm{liter}$ over an unspecified period of calcium-free perfusion. Before this, Ruano-Arroyo et al., (7) used isotope techniques to demonstrate that cell sodium content was related to cellular calcium, potassium loss, and decreased contractile function during calcium readmission. Additionally, this group recently demonstrated that the magnitude of calcium oscillations measured as the frequency of intensity fluctuations in scattered laser light, was highly dependent on conditions that alter $\alpha \mathrm{Na}^{\mathrm{i}}$ (29): Recently, Busselen demonstrated that changes in total cell sodium content affected myoglobin release (an index of the severity of the paradox) only at lower temperatures (24). Nonetheless, in most models, it seems apparent that the calcium reentry seen during calcium reperfusion is related to cellular sodium loading.

In these experiments we were able to document that changes in the sodium activity gradient were related to the development of calcium readmission contracture. The continuous measurement of the sodium gradient allowed for a prospective strategy to evaluate the role that an increase in $\alpha \mathrm{Na}^{\mathrm{i}}$ plays before contracture. These data suggested that an increase in $\alpha \mathrm{Na}^{\mathrm{i}}$ was a necessary condition for the calcium reperfusion contracture. The data are consistent with the hypothesis that the sodium-calcium exchange is responsible for the calcium reentry seen during the calcium paradox. Other possible mechanisms for calcium entry have been proposed $(4,11)$. Alto and Dhalla (5) suggested that calcium entered via a leaky membrane. Rich and Langer (11) suggested that changes in calcium permeability at the level of the glycocalyx or lipid bilayer were responsible. More recently Tunstall et al. (12) provided evidence in fish and frog atria that calcium entry appeared to be through the sodium calcium exchanger. The experimental paradigm used in their studies demonstrated that contracture tension and abnormal action potentials returned to baseline after a period of calcium reperfusion, thus suggesting that membrane damage or leak was not responsible for the calcium entry. 
The data generated in the present study are quite consistent with the sodium calcium exchange model being operative during readdition of calcium, but the mechanism of sodium entry during the calcium-free period was in question. These preparations were done under nonstimulated conditions and as such the contribution of both the sodium inward current and the calcium slow inward current would be questionable. Additionally, in these preparations, depolarization ranged from $-60 \pm 10 \mathrm{mV}$, a range which should inhibit the sodium channel. That the sodium channel was not involved in the sodium entry during the calcium-free period was confirmed by the experiments that used $10^{-4} \mathrm{M}$ tetrodotoxin. In the preparations that used tetrodotoxin, there was very little change in the sodium gain during the calcium-free period compared with the solutions with no tetrodotoxin.

In frog atrial tissue at $20^{\circ} \mathrm{C}$, Tunstall et al. (12) suggested that the principal mechanism for sodium entry was through a modified calcium channel. Their data corroborated the work of Levi and De Felice, which demonstrated that under certain conditions the calcium channel will conduct sodium ions (26). More recently Chapman et al. (22) provided further evidence that suggested that in sheep Purkinje fibers, sodium entered during the calcium-free period through the calcium channel. In the ferret preparation at $37^{\circ} \mathrm{C}, 10^{-5} \mathrm{M}$ nitrendipine, a relatively specific slow channel blocker, did not affect sodium entry or the subsequent contracture. The nitrendipine data, in this nonbeating muscle preparation, would suggest that the slow channel was not involved, or that in a nonbeating preparation nitrendipine is unable to block the slow channel (use dependency). It would appear, however, that nitrendipine has little use-dependent calcium channel blockade, and may have a decided preference for the rested state (30). The experiments that used two separate concentrations of amiloride are helpful in this regard. Amiloride at relatively low concentrations $\left(10^{-6}\right.$ M) had very little effect on sodium gain or calcium reperfusion contracture. In this concentration range, amiloride blocks sodium hydrogen exchange, and at the very least these experiments would suggest that the sodium gain is not through the sodium hydrogen exchange mechanism $(31,32)$. In higher concentrations $\left(10^{-3} \mathrm{M}\right)$ the gain in sodium was completely obliterated and with it the calcium readdition contracture. At these higher concentrations of amiloride, sodium-calcium exchange is significantly inhibited (33). It is possible, that at these higher concentrations of amiloride, blockade of slow channel may exist. It cannot be stated with certainty that some sodium entry through a modified slow calcium channel exists. Additionally, we used dichlorobenzamil, a more potent $\mathrm{Na}^{+} / \mathrm{Ca}^{2+}$ exchange blocker, which had an effect similar to amiloride. Nonetheless, it seems apparent that amiloride and its analogues are not entirely specific in their cation exchange blockade. As such, the inhibition of sodium gain cannot unequivocally be accounted for by $\mathrm{Na}^{+} / \mathrm{Ca}^{2+}$ exchange blockade $(31-34)$.

In this nonbeating preparation, calcium was not directly measured and it is noteworthy that the time between reperfusion with calcium and the onset of contracture is on the order of minutes. This contracture at this temperature appears to be irreversible. As such, it is probable that the translocation of sodium and calcium that occurs at reperfusion acts as a trigger for the subsequent irreversible damage seen. This may occur from changes in the glycocalyx, or through changes in mitochondrial calcium uptake $(10,11,34)$.
In summary, these studies show that significant gain in the intracellular sodium activity is a prerequisite to the contracture seen in the calcium paradox. In these nonbeating preparations, the data are consistent with sodium entry through the sodium calcium exchange countertransporter during the calcium-free state and with calcium entry during calcium reperfusion. The data demonstrate that the translocation of sodium and calcium precede the onset of contracture on the order of minutes, suggesting that the ion translocation acts as a trigger for subsequent damage. The data, however, do not exclude substantial sodium gain through a modified calcium channel.

\section{Acknowledgments}

The author wishes to acknowledge Dr. Myron L. Weisfeldt and Dr. Edward G. Lakatta for their review of this manuscript.

This research was supported in part by the National Institutes of Health (NIH) Ischemic Heart Disease SCOR HL-17655, and NIH New Investigator Research Award HL-33904.

\section{References}

1. Zimmerman, A. N. E., and W. C. Hulsmann. 1966. Paradoxical influence of calcium ions on the permeability of the cell membranes in the isolated rat heart. Nature (Lond.). 211:646-647.

2. Zimmerman, A. N. E., W. Daemes, W. C. Hulsmann, J. Snijder, E. Weisse, and D. Durrer. 1967. Morphological changes in heart muscle caused by successive perfusion with calcium-free and calcium containing solutions. Cardiovasc. Res. 1:201-209.

3. Hearse, D. J., S. M. Humphrey, and S. M. Bullock. 1978. The oxygen paradox in calcium paradox: two facets of the same problem. $J$. Mol. Cell. Cardiol. 10:641-688.

4. Grinwald, P. M., and W. G. Nayler. 1981. Calcium entry in the calcium paradox. J. Mol. Cell. Cardiol. 13:867-880.

5. Alto, L. E., and N. S. Dhalla. 1979. Myocardial cation contents during induction of calcium paradox. Am. J. Physiol. 237:H713H719.

6. Chapman, R. A., G. C. Rodrigo, J. Tunstal, R. J. Yates, and R. Busselen. 1984. The calcium paradox of the heart: a role for intracellular sodium ions. Am. J. Physiol. 247:H874-H879.

7. Ruano-Arroyo, G., G. Gerstenblith, and E. G. Lakatta. 1984. "Calcium paradox" in the heart is modulated by cell sodium during the calcium free period. J. Mol. Cell. Cardiol. 16:783-793.

8. Walford, G. D., G. Gerstenblith, and E. G. Lakatta. 1984. Effect of sodium on calcium-dependent force in unstimulated rat cardiac muscle. Am. J. Physiol. 246:H222-H231.

9. Bielecki, K. 1969. The influence of changes in pH of the perfusion fluid on the occurrence of the calcium paradox in the isolated rat heart. Cardiovasc. Res. 3:268-271.

10. Yates, J. C., and N. S. Dhalla. 1975. Structural and functional changes associated with failure and recovery of hearts after perfusion with calcium free medium. J. Mol. Cell. Cardiol. 7:91-103.

11. Rich, T. L., and G. A. Langer. 1982. Calcium depletion in rabbit myocardium: calcium paradox protection by hypothermia and cation substitution. Circ. Res. 51:131-141.

12. Tunstall, J., P. Bussele, G. C. Rodrigo, and R. A. Chapman. 1986. Pathways for the movements of ions during calcium-free perfusion in the induction of the "calcium paradox." J. Mol. Cell. Cardiol. 18:241-254.

13. Deitmer, J. W., and D. Ellis. 1977. Changes in intracellular sodium activity of sheep heart Purkinje fibers. J. Physiol. (Lond.). 273:211-240.

14. Deitmer, J. W., and D. Ellis. 1985. The intracellular sodium activity of cardiac Purkinje fibres during inhibition and reactivation of the Na-K pump. J. Physiol. (Lond.). 248:C189-C202.

15. Sheu, S. S., and H. A. Fozzard. 1982. Transmembrane sodium 
$\mathrm{Na}^{+}-\mathrm{Ca}^{2+}$ electrochemical gradients in cardiac muscle in the relationship to force development. J. Gen. Physiol. 80:325-351.

16. Chapman, R. A., A. Coray, and J. A. S. McGugan. 1983. Sodium/calcium exchange in the mammalian ventricular muscle: a study with sodium-sensitive microelectrodes. J. Physiol. (Lond.). 343:253-276.

17. Lee, C. O., D. Y. Uhm, and K. Dresdner. 1980. Sodium-calcium exchange in rabbit heart muscle cells: direct measurement of sarcoplasmic $\mathrm{Ca}^{2+}$ activity. Science (Wash. DC). 209:699-701.

18. Marban, E., T. J. Rink, R. W. Tsien, and T. Y. Tsien. 1980. Free calcium in heart muscle at rest and during contraction measured with $\mathrm{Ca}^{2+}$ sensitive microelectrodes. Nature (Lond.). 286:845-850.

19. Bers, D. M., and D. Ellis. 1982. Intracellular calcium and sodium activity in sheep heart Purkinje fibers. Effect of changes of external sodium and intracellular pH. Pfluegers Arch. Eur. J. Physiol. 393:171-178.

20. Allen, D. G., D. A. Eisner, M. J. Lab, and C. H. Orchard. 1983. The effects of low sodium solutions on intracellular calcium concentration and tension in ferret ventricular muscle. J. Physiol. (Lond.). 345:391-407.

21. Horackova, M., and G. Vassort. 1979. Sodium-calcium exchange in regulation at cardiac contractility. J. Gen. Physiol. 73:403424.

22. Chapman, R. A., H. A. Fozzard, I. R. Friedlander, and C. T. January. 1986. Effects of $\mathrm{Ca}^{2+} / \mathrm{Mg}^{2+}$ removal on $\alpha \mathrm{Na}^{\mathrm{i}}, \alpha \mathrm{K}^{\mathrm{i}}$, and tension in cardiac Purkinje fibers. Am. J. Physiol. 251:C920-C927.

23. Gadsby, D. C. 1980. Activation of electrogenic $\mathrm{Na}^{+} / \mathrm{K}^{+}$exchange by extracellular $\mathrm{K}^{+}$in canine cardiac Purkinje fibers. Proc. Natl. Acad. Sci. USA. 77:4035-4039.

24. Busselen, R. 1987. Effects of sodium on the calcium paradox in rat hearts. Pfluegers Arch. Eur. J. Physiol. 408:458-464.
25. Guarnieri, T. 1987. Intracellular sodium-calcium dissociation in early contractile failure in hypoxic ferret papillary muscle. J. Physiol. (Lond.). 388:449-465.

26. Levi, R., and L. J. De Felice. 1986. Sodium-conducting channels in cardiac membranes in low calcium. Biophys. J. 50:5-9.

27. Steiner, R. A., M. Oehme, D. Ammann, and W. Simon. 1979. Neutral carrier sodium ion-sensitive microelectrode for intracellular studies. Anal. Chem. 51:351-353.

28. Baumgartern, C. M., C. J. Cohen, and T. J. McDonald. 1981. Heterogeneity of intracellular potassium activity and membrane potential in hypoxic guinea pig ventricle. Circ. Res. 49:1181-1189.

29. Kort, A. A., E. G. Lakatta, E. Marban, M. Stern, and W. G. Wier. 1985. Fluctuations in intracellular calcium concentrations and their effect on tonic tension in canine cardiac Purkinje fibers. J. Physiol. (Lond.). 367:291-308.

30. Lee, K. S., and R. W. Tsien. 1983. Mechanism of calcium channel blockade by verapamil, D600, diltiazem and nitrendipine in single dialyzed heart cells. Nature (Lond.). 302:790-794.

31. Vigne, P., C. Frelen, E. J. Cragoe, and M. Lazdunski. 1982. Structure-activity relationships of amiloride and certain of its analogs in relation to the blockade of the $\mathrm{Na}^{+} / \mathrm{H}^{+}$exchange system. $\mathrm{Mol}$. Pharmacol. 25:131-136.

32. Benos, D. J. 1982. Amiloride: a molecular probe of sodium transport in tissue and cells. Am. J. Physiol. (Cell). 242:C131-C145.

33. Floreavi, M., and S. Luciani. 1984. Amiloride: the relationship between cardiac effects and inhibition of $\mathrm{NA}^{+} / \mathrm{CA}^{2+}$ exchange. Eur. $J$. Pharmacol. 105:317-322.

34. Roteuatn, S., H. Jodalen, and J. Rol. 1986. Myocardial cAMP and calcium levels in the calcium paradox. Basic Res. Cardiol. 81:430-435. 